\title{
An empirical method to measure the relative efficiency of dairy producers using deterministic frontier analysis
}

\author{
Shahram RostamPour
}

Department of Management Science, Islamic Azad University, Central Branch, Tehran, Iran

\begin{tabular}{l}
\hline A R T I C L E I N F O \\
\hline Article history: \\
Received June 30, 2011 \\
Received in Revised form \\
August, 25, 2011 \\
Accepted 28 August 2011 \\
Available online \\
1 September 2011 \\
\hline Keywords: \\
Distribution free analysis \\
Measuring relative efficiency \\
Dairy industry \\
Stochastic frontier analysis \\
Data envelopment analysis \\
Deterministic frontier analysis
\end{tabular}

\section{A B S T R A C T}

\begin{abstract}
The purpose of this paper is to measure the relative efficiencies of various cow husbandries. The proposed model of this paper uses deterministic frontier analysis to measure the performance of different units responsible for taking care of cows. We gather the necessary information of all units including number of cows, amount of internet usage, number of subunits for taking care of cows, amount of forage produced in each province for grazing livestock and average hour per person training courses as independent variables and consider the amount of produced milk as dependent variable. The necessary information are collected from all available units located in different provinces of Iran and the production function is estimated using a linear programming model. The results indicate that the capital city of Iran, Tehran, holds the highest technical efficiency, the lowest efficiency belongs to province of Ilam and other provinces mostly performs poorly.
\end{abstract}

\section{Introduction}

Milk is one of the necessary foods in the basket of anyone in the world since it contains the necessary minerals required by human body such as Calcium. There are several dairy products built from milk and it plays an important role on people's daily food. The important issue is that this industry in Iran heavily depends on government's regulation and there is an increasing competition among all active units. One alternative to help this industry is to encourage them to increase their efficiencies by optimally using their resources. In other words, the local government knows well that any increase on milk price could easily hike inflation rate and they do not let milk producers increase their rates. An alternative solution is to provide low rate loans to help them restructure their businesses and lower their expenses. There are normally different techniques for measuring the relative efficiency of different similar units but most of them use some inputs and/or outputs to perform such analysis. We can divide them into two different techniques of parametric and non-parametric methods as follows,

\footnotetext{
* Corresponding author. Tel: +989359821267

E-mail addresses: shrrsp@yahoo.com (S. Rostampour) 
1. Parametric methods: These methods are based on the econometric estimation of the cost of production function, which needs the definition of a priori of the functional form of the efficient frontier and a good example of such method is stochastic frontier analysis (SFA) introduced by $\mathrm{F}$ re et al. (1993). The method has been widely used among many practitioners (Coelli et al., 2005). The other technique is distribution free approach for measuring the relative efficiency of different units (Berger, 1993, Troutt et al., 2005). There is also another technique called determinitic frontier analysis (DFA) developed by Aigner et al. (1977). They estimated a deterministic frontier production function using Cobb-Douglas production function.

2. Non-parametric methods: These methods are based on mathematical programming approaches. In this case the relative efficiency of similar farms is determined based on the implementation of linear programming techniques and a good example of this technique includes data envelopment analysis (DEA) introduced by Charnes et al. $(1978,1994)$.

There are many real-world case studies, where different parametric and non-parametric methods are used to measure the relative efficiency of various units (Roghanian \& Foroughi, 2010). Sedik et al. (1999) considered how Russian corporate farm efficiency had changed during the years from 1991 to 1995. According the their studies, Efficiency scores can be explained by several economic and institutional factors, including farm size, softness of the budget constraint, deterioration in farm terms of trade and oblast-level specialization of production.

Dios-Palomares and Martínez-Paz (2011) studied the level of technical efficiency in the olive oil industry from a multi-output perspective, and examined olive oil production in terms of quantitative and qualitative figures. They measured the relative technical efficiency indices and set specific efficiency indices for both the quality of the oil produced and the environmental influences of the production process. Iribarren et al. (2011) used life cycle assessment and DEA method for measuring the relative efficiency of farm units and reported that they could reduce up to $38 \%$ for input consumption levels, leading to impact reductions above $20 \%$ for every environmental impact category. Dimara et al. (2008) investigated the effects of productive efficiency on the survival of factories in the Greek food sector. Technical and scale efficiency scores were computed within a DEA method and were used as explanatory variables in a parametric (Weibull) survival model. They reported that high technical efficiency could increase the median survival time and it could lower the hazard rate of exit. They also reported that the effects of technical and scale efficiency on the survival of firms in the food sector are of particular relevance to food policy makers.

In this paper, we present an empirical analysis to measure the relative efficiency of various cow husbandries using deterministic frontier analysis (DFA). This paper first presents the problem statement of the proposed model in section 2 and section 3 presents the experimental results for a real-world case study. Finally, concluding remarks are given in the last to summarize the contribution of the paper.

\section{Problem statement}

Deterministic frontier analysis (DFA) uses a simple implementation of Cobb-Douglas function (Houthakker, 1955) as follows,

$\ln Y_{i}=\sum_{i=1}^{m} \beta_{i} X_{i j}-\varepsilon_{i}, \quad j=1, \cdots, n$

where $X_{i j}$ represent all independent factors affecting the efficiency of the production, $\beta_{i}$ represent the coefficients to be estimated, $\ln Y_{i}$ is the $\log$ of production function and $\varepsilon_{i}$ is the error term. According

to Eq. (1) $\ln Y_{i}$ is maximized when $\ln Y_{i}=\ln \hat{Y}_{i}$. Therefore, we could minimize the error term through the following linear programming problem, 
$\min \sum_{j=1}^{m} \varepsilon_{i}$

subject to

$\ln \hat{Y}_{i} \geq \ln Y_{i}$

In model (2) we can replace $\sum_{j=1}^{m} \varepsilon_{i}$ from Eq. (1), which yields the following linear programming model,

$\min \beta_{0} X_{0}+\cdots \beta_{m} X_{m}$

subject to

$\beta_{0} X_{01}+\cdots+\beta_{m} X_{m 1}$

$\beta_{0} X_{0 n}+\cdots+\beta_{m} X_{m n}$

The optimal solution of Eq. (3) yields $\hat{Y}_{i}$ and could help calculate technical efficiency (TE) by $T E=\frac{Y_{j}}{\hat{Y}_{j}}$

\section{Case study}

The proposed study of this paper uses number of cows, amount of internet usage, number of subunits for taking care of cows, amount of forage produced in each province for grazing livestock and average hour per person training courses as independent variables and consider the amount of produced milk as dependent variable. In our study, all numbers are gathered from different provinces of Iran and Table 1 summarizes all the input information.

Table 1

The input information of the proposed model

\begin{tabular}{|c|c|c|c|c|c|c|c|c|c|c|c|c|}
\hline Province & MP & NoS & $\mathrm{NoC}$ & $\mathrm{AIU}$ & AFP & TLU & $\ln \mathrm{MP}$ & $\ln \mathrm{NoS}$ & $\ln \mathrm{NoC}$ & $\ln \mathrm{AIU}$ & $\ln \mathrm{AFP}$ & $\ln \mathrm{TLU}$ \\
\hline 1.East Azarbayjan & 2070000 & 4 & 495 & 20 & 598 & 10 & 12.24 & 1.39 & 6.20 & 3 & 6.39 & 2.3 \\
\hline 2.West Azarbayjan & 978910 & 29 & 1299 & 6 & 610 & 93 & 13.79 & 3.37 & 7.17 & 1079 & 6.41 & 4.53 \\
\hline 3. Ardebil & 193170 & 13 & 476 & 1 & 238 & 10 & 12.17 & 2.57 & 6.17 & 0 & 5.47 & 2.3 \\
\hline 4. Esfahan & 2521900 & 23 & 2724 & 3 & 465 & 10 & 14.74 & 3.14 & 7.91 & 1.1 & 6.14 & 2.3 \\
\hline 5. Ilam & 172400 & 6 & 389 & 8 & 181 & 191 & 12.06 & 1.79 & 5.99 & 2.08 & 5.2 & 5.25 \\
\hline 6. Tehran & 9988420 & 21 & 5841 & 50 & 75 & 21 & 16.12 & 3.04 & 8.67 & 3.91 & 4.32 & 3.04 \\
\hline 7. Bakhtiari & 330500 & 12 & 634 & 1 & 78 & 205 & 12.71 & 2.49 & 6.45 & 0 & 4.36 & 5.32 \\
\hline 8. South Khorasan & 279000 & 2 & 510 & 1 & 284 & 234 & 12.54 & 0.69 & 6.23 & 0 & 5.65 & 5.46 \\
\hline 9. Razavi Khorasan & 5169550 & 41 & 5692 & 51 & 284 & 258 & 15.46 & 3.71 & 8.65 & 3.93 & 5.65 & 5.55 \\
\hline 10. North Khorasan & 399850 & 10 & 513 & 1 & 284 & 346 & 12.89 & 2.30 & 6.24 & 0 & 5.65 & 5.85 \\
\hline 11. Khozestan & 124400 & 1 & 30 & 60 & 223 & 10 & 11.73 & 0 & 3.40 & 4.09 & 5.41 & 2.3 \\
\hline 12. Zanjan & 137800 & 3 & 206 & 4 & 138 & 81 & 11.83 & 1.09 & 5.33 & 1.39 & 4.93 & 4.39 \\
\hline 13. Semnan & 972375 & 10 & 890 & 1 & 488 & 469 & 13.79 & 2.30 & 6.79 & 0 & 6.19 & 6.15 \\
\hline 14. Sistan & 267600 & 3 & 620 & 1 & 527 & 10 & 12.49 & 1.09 & 6.43 & 0 & 6.27 & 2.3 \\
\hline 15. Fars & 1558730 & 21 & 1746 & 30 & 1432 & 3700 & 14.26 & 3.04 & 7.47 & 3.40 & 7.27 & 8.22 \\
\hline 16. Qazvin & 2386600 & 11 & 1999 & 12 & 136 & 429 & 14.69 & 2.4 & 7.6 & 2.49 & 4.91 & 6.06 \\
\hline 17. Qom & 2355751 & 15 & 1862 & 30 & 39 & 635 & 14.67 & 2.71 & 7.53 & 3.40 & 3.66 & 6.45 \\
\hline 18. Kordestan & 291400 & 9 & 358 & 1 & 422 & 212 & 12.58 & 2.2 & 5.88 & 0 & 6.05 & 5.36 \\
\hline 19. Kerman & 466200 & 12 & 840 & 1 & 399 & 218 & 13.05 & 2.49 & 6.73 & 0 & 5.99 & 5.38 \\
\hline 20. Kermanshah & 320860 & 11 & 588 & 1 & 264 & 142 & 12.68 & 2.4 & 6.38 & 0 & 5.58 & 4.96 \\
\hline 21. Boyerahmad & 231690 & 7 & 422 & 1 & 438 & 394 & 12.35 & 1.95 & 6.05 & 0 & 6.08 & 5.98 \\
\hline 22. Golestan & 1725900 & 40 & 402581 & 1 & 149 & 363 & 14.36 & 3.69 & 7.86 & 0 & 5 & 5.89 \\
\hline 23. Gilan & 222400 & 6 & 301 & 14 & 88 & 1266 & 12.31 & 1.79 & 5.71 & 2.64 & 4.48 & 7.14 \\
\hline 24. Lorestan & 318000 & 6 & 460 & 1 & 246 & 271 & 12.67 & 1.79 & 6.13 & 0 & 5.51 & 5.6 \\
\hline 25. Mazandaran & 213900 & 6 & 348 & 1 & 286 & 501 & 12.27 & 1.79 & 5.85 & 0 & 5.66 & 6.22 \\
\hline 26. Markazi & 476250 & 9 & 589 & 1 & 226 & 129 & 13.07 & 2.2 & 6.39 & 0 & 5.42 & 4.86 \\
\hline 27. Hamedan & 1723950 & 14 & 1904 & 1 & 97 & 587 & 14.36 & 2.64 & 7.55 & 0 & 4.57 & 6.38 \\
\hline 28. Yazd & 1008623 & 21 & 1297 & 100 & 120 & 221 & 13.82 & 3.04 & 7.17 & 4.61 & 4.79 & 5.4 \\
\hline Sum & & 366 & 35614 & 403 & 8815 & 11091 & & & & & & \\
\hline Average & & 13.07 & 1271.93 & 14.4 & 315 & 396 & & & & & & \\
\hline
\end{tabular}


The information are collected from a survey during the year 2010 by statistical organization of Iran. As we can observe, there are 753 units operating during that year with over 131637 cows producing milk. Based on the survey there were 523 active units and the others were inactive and 461 units working as industrialized complex.

The implementation of the proposed model given in Eq. (3) yields $\operatorname{Ln} \hat{Y}_{\mathrm{j}}=16.12$ or $\hat{\mathrm{Y}}_{\mathrm{j}}=$ 10002329.86. Therefore, technical efficiencies of all units are calculated in Table 2.

Table 2

Technical efficiency of all units

\begin{tabular}{lccc}
\hline Province & Actual Production & Efficient production & Relative efficiency \\
\hline 1.East Azarbayjan & 2070000 & 10002329.86 & 0.206952 \\
2. West Azarbayjan & 978910 & 10002329.86 & 0.097868 \\
3. Ardebil & 193170 & 10002329.86 & 0.019313 \\
4. Esfahan & 2521900 & 10002329.86 & 0.252131 \\
5. Ilam & 172400 & 10002329.86 & 0.017236 \\
6. Tehran & 9988420 & 10002329.86 & 0.998609 \\
7. Bakhtiari & 330500 & 10002329.86 & 0.033042 \\
8. South Khorasan & 279000 & 10002329.86 & 0.027894 \\
9. Razavi Khorasan & 5169550 & 10002329.86 & 0.516835 \\
10. North Khorasan & 399850 & 10002329.86 & 0.039976 \\
11. Khozestan & 124400 & 10002329.86 & 0.012437 \\
12. Zanjan & 137800 & 10002329.86 & 0.013777 \\
13. Semnan & 972375 & 10002329.86 & 0.097215 \\
14. Sistan & 267600 & 10002329.86 & 0.026754 \\
15. Fars & 1558730 & 10002329.86 & 0.155837 \\
16. Qazvin & 2386600 & 10002329.86 & 0.238604 \\
17. Qom & 2355751 & 10002329.86 & 0.23552 \\
18. Kordestan & 291400 & 10002329.86 & 0.029133 \\
19. Kerman & 466200 & 10002329.86 & 0.046609 \\
20. Kermanshah & 320860 & 10002329.86 & 0.032079 \\
21. Boyerahmad & 231690 & 10002329.86 & 0.023164 \\
22. Golestan & 1725900 & 10002329.86 & 0.17255 \\
23. Gilan & 222400 & 10002329.86 & 0.022235 \\
24. Lorestan & 318000 & 10002329.86 & 0.031793 \\
25. Mazandaran & 213900 & 10002329.86 & 0.021385 \\
26. Markazi & 476250 & 10002329.86 & 0.047614 \\
27. Hamedan & 1723950 & 10002329.86 & 0.172355 \\
28. Yazd & 1008623 & 10002329.86 & 0.100839 \\
Average & & & 0.131777 \\
Maximum & & & 0.998609 \\
Minimum & & & 0.012437 \\
\hline & & & \\
\hline
\end{tabular}

As we can observe from the results of Table 2, most of units are relatively inefficient and Tehran is the only province, which remains efficient. The other provinces were mostly operating poorly with relative efficiency of less than 20 percent. There are different reasons for having so many inefficient units such as dryness events, governmental regulation, etc. Presently, the government subsidizes milk production on one hand and the producers are allowed to increase their prices. Therefore, milk producers face with shortage of money and most of them have not been able to renovate their equipments. This hurts many businesses since they cannot easily layoff their staff, restructure their business model and cope with present conditions. The government has set a new rule to eliminate the 
subsidization program and deregulate the industry. This could help producers increase their prices but this deregulation could have other consequences, which could hurt this industry.

\section{Conclusion}

In this paper, we have presented an empirical analysis to measure the relative efficiencies of different cow husbandries. The proposed model of this paper implemented a method called deterministic frontier analysis to measure the relative efficiencies of different units. We gathered the necessary information of all units including the number of cows, the amount of internet usage, the number of subunits for taking care of cows, the amount of forage produced in each province for grazing livestock and the average hour per person training courses as independent variables and considered the amount of produced milk as dependent variable. The information was collected from all available units located in different provinces of Iran and the production function was estimated using a linear programming model. The results indicated that the capital city of Iran, Tehran, holds the highest technical efficiency, the lowest efficiency belongs to province of Ilam and other provinces mostly maintain low efficiencies. There were different reasons for having inefficient units such as government regulation, dryness year. The present study suggests that government must carefully look for alternative solutions for helping this industry.

The present study used deterministic frontier analysis to measure the relative efficiencies but we could use other popular models to measure the relative efficiency of these units such as data envelopment analysis and stochastic frontier analysis. Obviously, it would be interesting to compare the performances of all these methods and we leave it as future research for interested researchers.

\section{Acknowledgment}

The authors would like to thank the anonymous referees for their constructive comments on earlier version of this paper.

\section{References}

Aigner, D.J., Lovell, C.A.K., \& Schmidt, P. (1977). Formulation and estimation of stochastic frontier production functions. Journal of Econometrics, 6, 21-37.

Berger, A. (1993). Distribution-free estimates of efficiency in the U.S. banking industry and tests of the standard distributional assumptions. Journal of Productivity Analysis, 4, 261-292.

Charnes A, Cooper, W. W., \& Rhodes, E. (1978). Measuring the efficiency of decision making units. European Journal of the Operational Research, 2, 429-444.

Charnes A, Cooper W. W., Lewin, A., \& Seiford, L. M. (1994). Data envelopment analysis: theory, methodology and applications. Massachusetts: Kluwer Academic Publishers.

Coelli, T.J., Rao, D.S.P., O'Donnell, C.J., Battese, G.E. (2005). An Introduction to Efficiency and Productivity Analysis, $2^{\text {nd }}$ Ed. Springer, ISBN 978-0-387-24266-8.

Dios-Palomares, R., \& Martínez-Paz, J.M. (2011). Technical, quality and environmental efficiency of the olive oil industry. Food Policy, 36(4),526-534.

Dimara, E., Skuras, D., Tsekouras, K., \& Tzelepis, D. (2008). Productive efficiency and firm exit in the food sector. Food Policy, 33(2), 185-196.

F re, R., Grosskopf, S., Lovell, C.A.K., \& Yaisawarng, S. (1993). Derivation of shadow prices for undesirable outputs: a distance function approach. Review of Economics and Statistics, 75, 374 380.

Houthakker, H.S. (1955). The Pareto distribution and the Cobb-Douglas production function in activity analysis. The Review of Economic Studies, 23 (1), 27-31. 
Iribarren, D., Hospido, A, Moreira, M. T., \& Feijoo, G. (2011). Benchmarking environmental and operational parameters through eco-efficiency criteria for dairy farms. Science of The Total Environment, 409(10), 1786-1798.

Roghanian, E. \& Foroughi, A. (2010). An empirical study of Iranian regional airports using robust data envelopment analysis. International Journal of Industrial Engineering Computations, 1(1), 65-72.

Sedik, D., Trueblood, M., \& Arnade, C. (1999). Corporate Farm Performance in Russia, 1991-1995: An Efficiency Analysis. Journal of Comparative Economics, 27(3), 514-533.

Troutt, M.D., Hu, M.Y., \& Shanker, M.S. (2005). A distribution-free approach to estimating best response values with application to mutual fund performance modeling. European Journal of Operational Research, 166(2), 520-527. 